\title{
Pathological and immunohistochemical study of colon cancer. Evaluation of markers for colon cancer stem cells
}

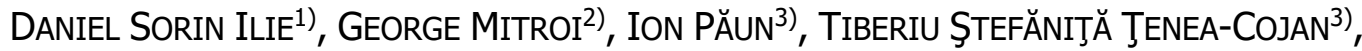 \\ CARMEN NEAMTU ${ }^{4}$, BOGDAN DAN TOTOLICI ${ }^{4}$, KONSTANTINOS SAPALIDIS ${ }^{5}$, \\ STELIAN ŞTEFĂNITĂ MOGOANTĂ ${ }^{3)}$, ADRIAN MUREA ${ }^{1)}$
}

\author{
1) PhD Student, Doctoral School, Department of Histology, University of Medicine and Pharmacy of Craiova, \\ Romania \\ 2) Department of Urology, University of Medicine and Pharmacy of Craiova, Romania \\ 3) Department of Surgery, University of Medicine and Pharmacy of Craiova, Romania \\ 4) Department of Surgery, Faculty of Medicine, Vasile Goldiş Western University of Arad, Romania

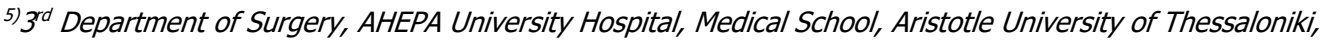 \\ Thessaloniki, Greece
}

\begin{abstract}
Colorectal cancer is a major public health problem worldwide with increasing morbidity and mortality. Numerous exogenous and endogenous factors are involved in colorectal carcinogenesis: age, sex, diet, smoking, alcohol consumption, exposure to harmful environmental factors, intestinal microbiota, bacterial and viral infections, the ability of the host immune system to respond, genetic factors, etc. The present study analyzed histopathologically and immunohistochemically a number of 36 cases of colorectal adenocarcinomas. The existence of an accentuated cell pleomorphism was noted, which corresponds to different clones of tumor cells, in the same tumor coexisting aspects of tubular adenocarcinoma, mucinous areas and even signet-ring cell. The tumor stroma was mainly of the desmoplastic type, but also of the lax type, more or less infiltrated with inflammatory cells. Evaluation of immunomarkers for cancer stem cells (CSCs) showed that none of the markers used alone [cluster of differentiation (CD)133, CD44, aldehyde dehydrogenase 1 family member A1 (ALDH1A1), CD24, CD26] show CSCs.
\end{abstract}

Keywords: colon cancer, adenocarcinoma, mucinous carcinoma, cancer stem cells, immunohistochemistry.

\section{a Introduction}

Within the last few decades, colorectal cancer (CRC) has become a worldwide major public health concern. This is mainly because it currently represents the second most diagnosed type of cancer in women and the third most common type of cancer in men, with an incidence rate that continues to grow [1-3].

CRC incidence differs from country to country, and this is mainly based on socioeconomic status. It is observed that higher socioeconomic status tends to be associated with a higher risk of developing CRC. Some parts of the world, with previous low incidence of $\mathrm{CRC}$, for example Eastern Europe and East Asia, have started to note an increasing incidence trend and are now reporting a higher number of CRC cases, a tendency that is attributed to changes in risk factors, lifestyle, and diet choices, which now lean towards a more westernized model [4].

According to data from the World Health Organization (WHO), CRC is responsible for approximately $13 \%$ of all cancer related deaths; worldwide this type of cancer causes approximately 600000 deaths per year $[4,5]$.

Colorectal carcinogenesis is a heterogeneous process characterized by various sets of molecular changes under the influence of factors like age, sex, diet, smoking, alcohol intake, exposure to hazardous environmental agents, gastrointestinal microbiota, bacterial and viral infections as well as the host's ability to respond to all these factors (host immunity) [6, 7]. Fairly recent, epidemiological studies have suggested that obesity and lifestyle choices (changeable risk factors) influence not only the risk of developing CRCs but also the morbidity and mortality associated with this malignancy $[8,9]$. It was also recently demonstrated that immunosuppression is involved in oncogenicity and also in the processes linked to tumor invasion and CRC metastasis [10].

Genetic factors have also been linked to the development of CRCs. Mutations of specific genes [oncogenes, tumor suppressor genes and genes involved in the deoxyribonucleic acid (DNA) repair process] can lead to CRC initiation [11]. It is these mutations that are also responsible for the development of cancer stem cells (CSCs), a process that happens through genetic mechanisms that affect the normal proliferation, differentiation, and self-renewal mechanisms $[12,13]$.

Therefore, CSCs are similar to normal stem cells (SCs) in a way that they possess the capacity for self-renewal and differentiation but at the same time are different from normal SCs through the fact that the mechanisms that

This is an open-access article distributed under the terms of a Creative Commons Attribution-NonCommercial-ShareAlike 4.0 International Public License, which permits unrestricted use, adaptation, distribution and reproduction in any medium, non-commercially, provided the new creations are licensed under identical terms as the original work and the original work is properly cited. 
govern these processes are deranged and therefore there is a perpetual expansion and production of abnormally differentiated cell descendants [14-16].

\section{Aim}

In this study, we aimed to analyze microscopic aspects of various forms of colon adenocarcinomas and also to evaluate the SC markers found within these tumors.

\section{ㅁ Materials and Methods}

The study material comprised of colon and rectal cancer fragments taken from patients that were diagnosed with colon cancer from a clinical, biological, and imagistic point of view and that underwent surgery within the Surgical Departments, Emergency County Hospital of Craiova and Railways Hospital of Craiova, Romania, between 2017 and 2020. Immediately after being removed, the fragments were placed in $10 \%$ neutral buffered formalin. In the end, from the period analyzed, we selected 36 cases of colorectal adenocarcinomas which were analyzed both pathologically and immunohistochemically. After finishing the fixation of the biomaterial, this was prepared for paraffin embedding according to the classical histological procedure.

This was followed by the sectioning of the paraffin embedded biomaterial with the use of HMB450 rotary microtome (Thermo Scientific) which was equipped with a Peltier paraffin cooler, which increased the consistency of the paraffin and allows for homogeneous and finer, 3-5 $\mu \mathrm{m}$ sections to be made. Also, the sectioning system has an additional transfer system which allows the sections to be transferred on water, which ultimately facilitates obtaining samples which are free of artefacts, like bending or overlapping. After the sections were placed on histological slides and were dried using a thermostat set at $37^{\circ} \mathrm{C}$ to increase adherence, they were stained using HematoxylinEosin (HE), Periodic Acid-Schiff (PAS)-Hematoxylin and with the use of Goldner-Szekely (GS) trichrome method.

For the immunohistochemical (IHC) analyses, the microtome sections were collected on special slides covered with poly-L-lysine, to increase the biomaterial's adherence to the histological slide. Afterwards, the immunohistochemistry protocol was applied which included deparaffinization (by placing the sections through three xylene baths, each lasting five minutes), rehydration (by placing the sections in decreasing concentrations of ethanol, namely $100 \%, 70 \%$ and $50 \%$ again five minutes per bath) and final hydration by immersing the sections in distilled water for 10 minutes.

The antigen retrieval was obtained by boiling the histological sections in the microwave in a special solution [Ethylenediaminetetraacetic acid (EDTA) or sodium citrate] at $650 \mathrm{~W}$ for 21 minutes (seven $\times$ three minutes cycles). Endogenous peroxidase blocking was obtained by incubating the biomaterial for 30 minutes in a $1 \%$ hydrogen peroxide solution, set at room temperature (RT), followed by abundant washing of the sections with distilled water and placing them in phosphate-buffered saline (PBS).
Blocking of specific binding sites was done by placing the biomaterial in a bath of $2 \%$ skimmed milk for 30 minutes.

After the above preparation, the primary antibody was applied to the biomaterial using the dilution recommended by the manufacturer followed by refrigeration at $4{ }^{\circ} \mathrm{C}$ for 12-14 hours (overnight) in a moist box (filter paper soaked with distilled water) to prevent sections from drying out.

The next day, the slides were taken out of the fridge and left at RT for 30 minutes followed by three cycles of abundant washing using PBS, each cycle lasting 15 minutes to eliminate the excess primary antibody. After this process, the secondary biotinylated antibody was applied to the sections for 30 minutes at RT, followed by a wash in $1 \%$ PBS (three five minutes washes), Streptavidin-Horseradish peroxidase (HRP) application for 30 minutes at RT, and lastly washing of the sections for 15 minutes in $1 \%$ PBS.

The actual detection of the IHC signal was done by incubating the sections with a peroxidase substrate, in the presence of a proton source - 3,3'-Diaminobenzidine $(\mathrm{DAB})$ - in the presence of $1 \%$ hydrogen peroxide. DAB oxidation formed a brown colored precipitate; the detection reaction was followed under a microscope, therefore after optimal staining, the sections were washed abundantly with PBS to stop the precipitation reaction. Then, the sections were stained using Mayer's Hematoxylin to mark the nuclei. Finally, the sections were dehydrated by placing them in three successive ethanol baths with increasing concentrations $(70 \%, 95 \%$ and $100 \%)$, clarifying them by placing sections in xylene (three washes of five minutes each) and covering them with xylene-based mounting media (DPX, Fluka) and protective glass slide.

For the IHC study, we utilized the following antibodies: anti-cluster of differentiation (CD)133 (mouse monoclonal antibody anti-CD133(3F10), NBP2-37741 clone, 1/200 dilution, Novus); anti-CD44 (monoclonal mouse antihuman CD44, phagocytic glycoprotein-1, DF1485 clone, 1/50 dilution, Dako); anti-aldehyde dehydrogenase 1 family member A1 (ALDH1A1) (ALDH1A1 antibody, PA5-32127 clone, 1/500 dilution, Invitrogen); anti-CD24 (polyclonal antibody anti-CD24, NBP1-46390 clone, 1/500 dilution, Novus); anti-CD26 [mouse anti-dipeptidyl peptidase-IV (DPPIV), NBP2-02154 clone, 1/50 dilution, Novus]; antip53 (monoclonal mouse anti-human p53 protein, DO-7 clone, 1/100 dilution, Dako).

\section{a Results}

The microscopic analyses have highlighted various histopathological aspects, which are specific to these types of tumors. All the 36 cases we analyzed were cases of adenocarcinomas. Out of the total number, 32 were typical adenocarcinomas, three were mucinous adenocarcinomas and one case was a signet ring cell adenocarcinoma.

Most adenocarcinomas were seen to be composed of anastomosed and ramified glandular structures with uneven lumen formed mainly of columnar cells and at times of caliciform cells sat on a basal membrane. The tumor glands presented either an empty lumen or a lumen that was 
occupied by necrotic cells, cytoplasmic fragments, nucleus residue and fibrous material, making the so called "dirty necrosis". The tumor epithelium has often presented with a cylindrical or pseudostratified aspect, with a cytoplasm that varied in abundancy and was inhomogeneous, with large hypochromic nuclei, vesicular nuclei or one or more small nucleolus.

Regarding the differentiation degree out of the 34 tubular adenocarcinomas, 31 were well- and moderately differentiated (Figure 1) and three were poorly differentiated (Figure 2).

Examination with the use of PAS-Hematoxylin staining has demonstrated that only a small part of tumor cells is capable of secreting PAS-positive mucin (polysaccharide, glycoprotein, glycolipids, proteoglycans), whilst most cells have lost this ability (Figure 3 ). The cells' pleomorphism indicates the existence of different clone cells within the same tumor.

The tumor stroma varied in size. Most often, the stroma had a desmoplastic aspect, with the development of a dense connective tissue, rich in fibroblasts and collagen fibers with an uneven disposition. At the same time, within the tumor stroma, there was a chronic inflammatory infiltrate formed of lymphocytes, plasma cells, macrophages, and dendritic cells. Sometimes, the stroma had an aspect similar to that of the loose connective tissue (Figure 4) or it was heavily infiltrated with immune cells (Figure 5).

All the CRC cases we studied were diagnosed in stages III and IV. The microscopic examination revealed on all samples the tumor penetration within the colon muscularis mucosae and even invasion of the pericolic fat. In some cases, there was even evidence of lymphatic dissemination (Figure 6).

Mucinous adenocarcinoma is characterized by large collections of extracellular mucins set within the extracellular environment, separated by tracts formed of fibers pertaining to connective cells and also inflammatory cells. The cellular component was greatly reduced in comparison with the mucin deposits and was formed of glands of irregular shapes, sizes, and disposition, anastomosed, or ramified with rare cellular atypia or rare mitosis (Figure 7). Sometimes, the epithelial component was formed of isolated tumor cells. Some areas of the tumor appeared completely free of malignant epithelium and appeared to be formed of mucin pools (lakes).

As far as the signet-ring cell adenocarcinoma, this was formed of individual or small group of cells characterized by clear cytoplasm and a round, oval, or misshapen nucleus placed in the periphery which made the tumor cells to have a characteristic signet ring aspect (Figure 8). The tumor stroma was formed of less connective tissue fibers and a bigger quantity of mucus.

We need to show that the microscopic aspects of analyzed adenocarcinomas were very varied. Some of the typical tubular adenocarcinomas contained areas of abundant mucus similarly to mucinous adenocarcinoma and even similar to signet-ring tumor cells. These microscopic aspects prove the great phenotypical variation of cells that form the structure of a colorectal tumor.
The IHC study aimed to analyze cell immunomarkers that are linked to CSCs and look at correlating their immunoexpression with that of other immunomarkers characteristic for tumor cells.

One of the first immunomarkers that was previously described as specific to CSC and that we also analyzed was CD133.

This immunomarker, also known as prominin-1, is a $120 \mathrm{kDa}$ transmembrane surface protein which is involved in multiple cell functions like tumorigenesis, chemo- and radio-resistance, cell metabolism, autophagy, and apoptosis. The immunoexpression of CD133 in CRC is one of the most important characteristics of SCs in colon cancer.

As we can observe from our images, in the case of well-differentiated colon cancer (Figure 9), the IHC reaction to $\mathrm{CD} 133$ was intense and present in almost all tumor cells, as well as some stromal cell.

CD44 is a multifunctional transmembrane protein, a receptor for hyaluronic acid, growth factors and cytokines. CD44+ tumor cells were less numerous then CD133+ cells, which makes us consider CD44 a much more selective immunomarker when compared to CD133, when it comes to the identification of CSC. This immunomarker showed a more intense IHC reaction in poorly differentiated adenocarcinomas and had a less intense reaction in well- and moderately differentiated adenocarcinomas (Figure 10).

ALDHs, especially ALDHA1, are considered an important immunomarker for SCs and especially CSCs. In our study, we noted a more intense immunoreaction from the colon adenocarcinoma tumor cells to ALDH1A1 immunomarker, regardless of the degree of tumor differentiation. This microscopic aspect indicates the presence of ALDH in all tumor cells forming the colon adenocarcinoma not only in CSC (Figure 11).

$\mathrm{CD} 24$ immunomarker is surface glycoprotein linked to CSCs in various types of cancer. In our study, in colon adenocarcinomas, the CD24 immunomarker showed an intense reaction within both the membrane and cytoplasm, especially in well-differentiated tumors. Therefore, this immunomarker, similarly to others, when taken in isolation, does not specifically mark CSCs (Figure 12).

The CD26 immunomarker is a $110 \mathrm{kDa}$ surface glycoprotein, with various functional properties including peptidase-like activity and also an immunomarker that plays an important role in tumor biology. The IHC reaction of colon adenocarcinoma tumor cells to CD26 was weak, but within the peritumoral stroma a number of cells presented with a more intense IHC signal (Figure 13).

The p53 immunomarker is often utilized in tumor studies to highlight changes of the TP53 tumor suppressing gene, one of the most important genes that plays an essential role in cancer initiation and development. In the studied adenocarcinomas, we noted that most tumor cells presented a positive and intense p53 immunoreaction (Figure 14). The tumor cells' positive reaction to p53 immunomarker was often associated with a positive reaction to CD133 and ALDH1A1 immunomarkers. 


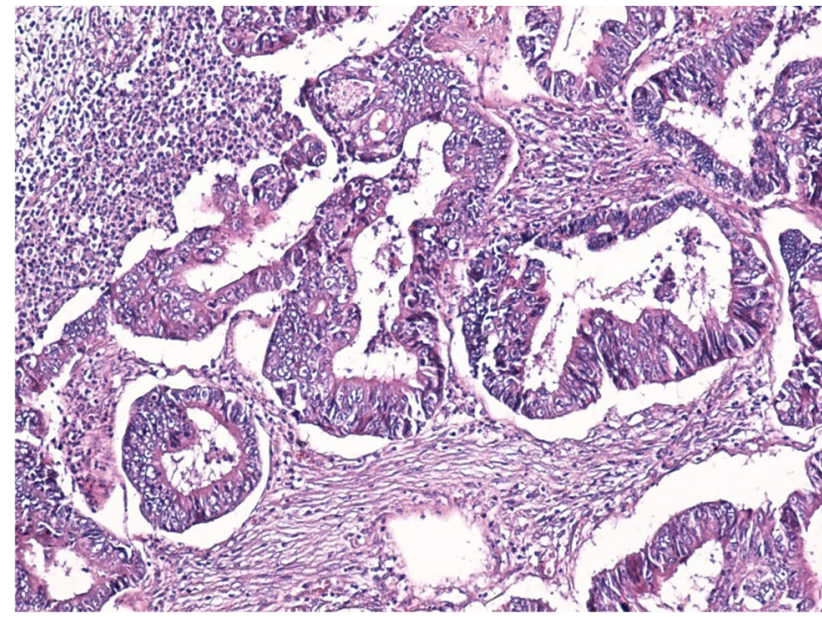

Figure 1 - Image of well-differentiated adenocarcinoma with desmoplastic stroma and a moderate amount of inflammatory infiltrate. $\mathrm{HE}$ staining, $\times 100$. HE: Hematoxylin-Eosin.

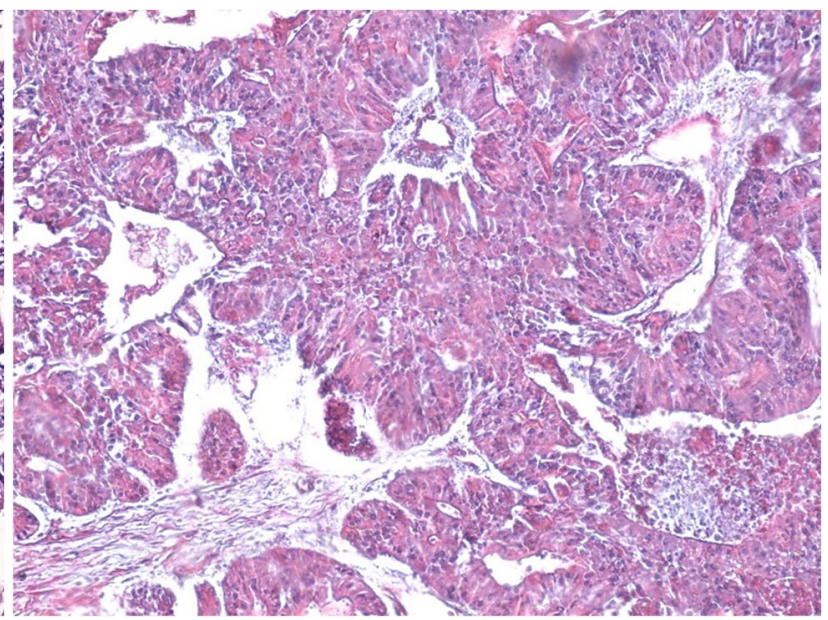

Figure 2 - Poorly differentiated colon adenocarcinoma. GS trichrome staining, ×100. GS: Goldner-Szekely.

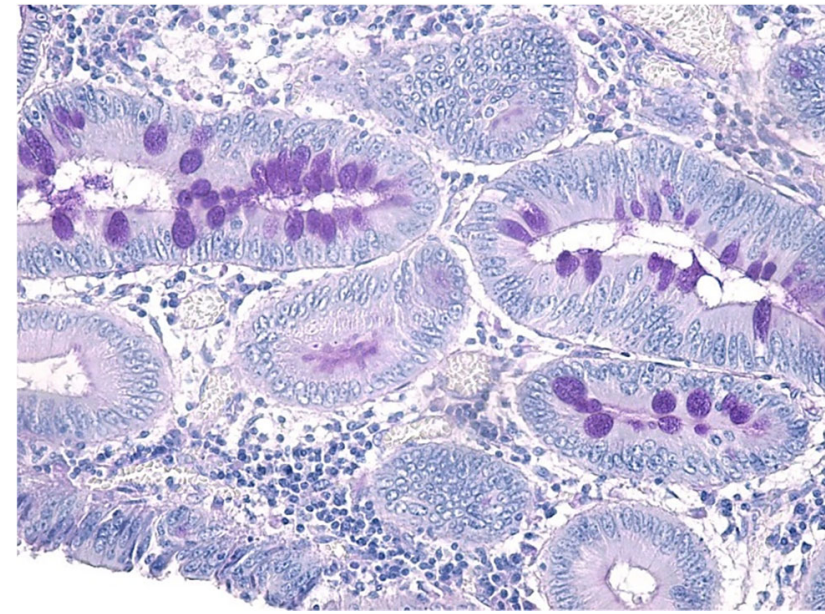

Figure 3 - Moderately differentiated adenocarcinoma formed of glands characterized by extensive cellular pleomorphism; some cells have retained the capacity to synthesize PAS-positive mucosubstances. PASHematoxylin staining, ×200. PAS: Periodic Acid-Schiff.

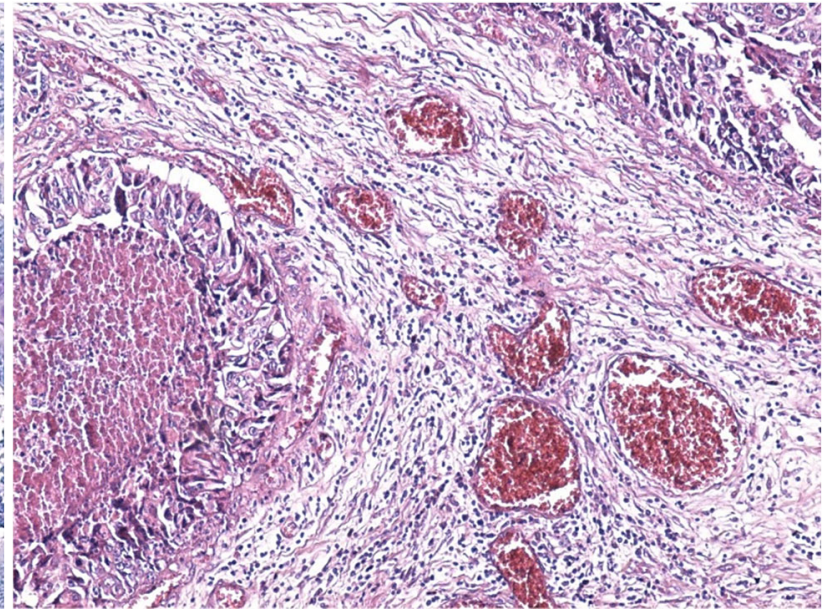

Figure 4 - Tumor stroma formed of loose connective tissue with numerous congested blood vessels, infiltrated with lymphocytes, plasma cells and macrophages. $\mathrm{HE}$ staining, $\times 100$.

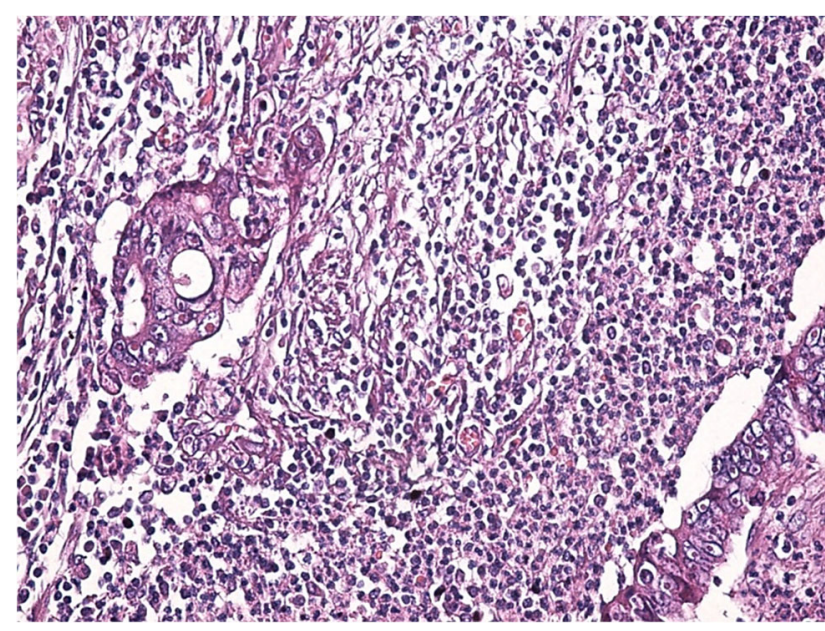

Figure 5 - Tumor stroma heavily infiltrated with inflammatory cells. $\mathrm{HE}$ staining, $\times 200$.

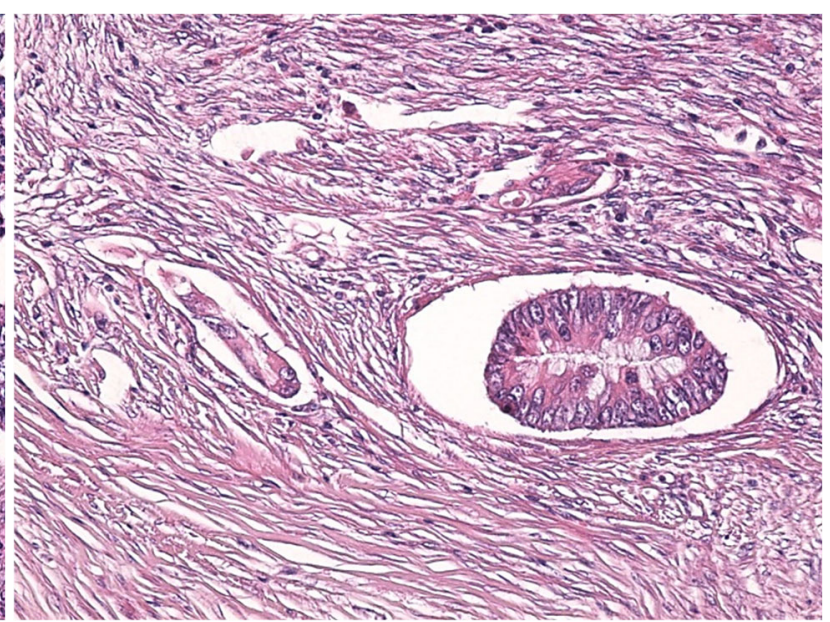

Figure 6-Tumor cells disseminated through the lymphatic pathway. HE staining, $\times 100$. 


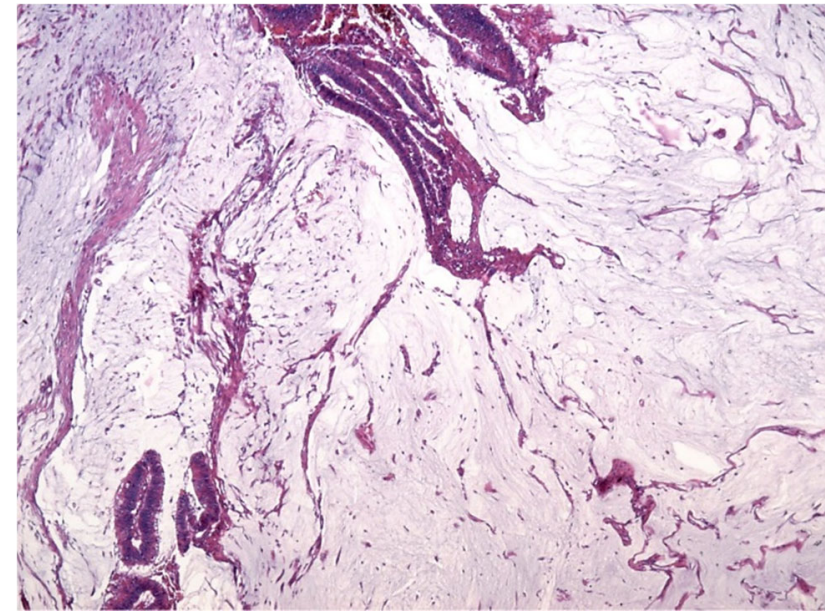

Figure 7 - Mucinous adenocarcinoma, overview. $\mathrm{HE}$ staining, $\times 40$.

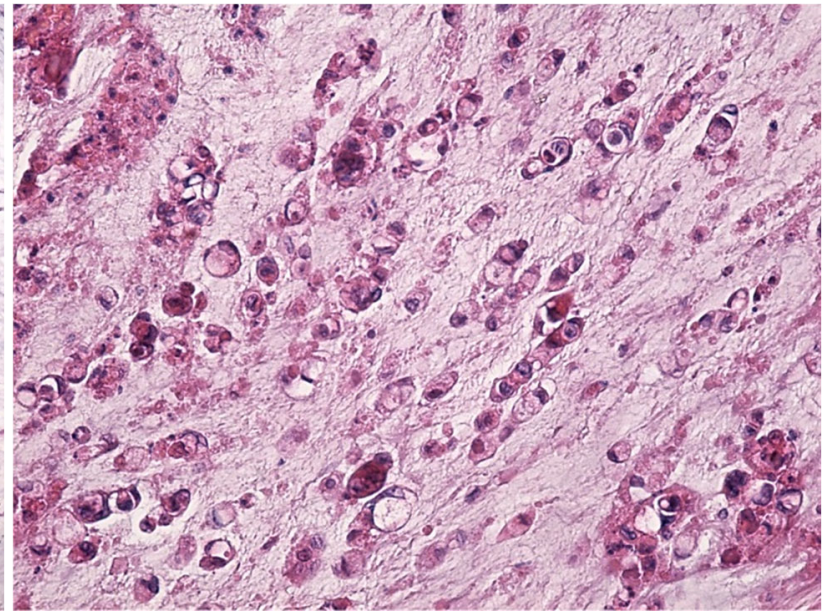

Figure 8 - Signet-ring cell adenocarcinoma. HE staining, $\times 200$.

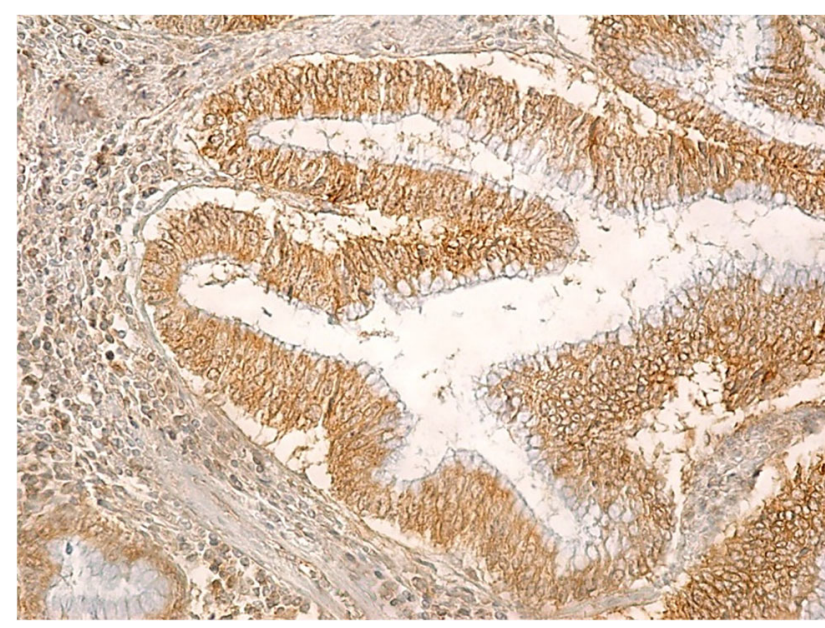

Figure 9 - Well-differentiated colon adenocarcinoma with an intense immunohistochemical reaction within the tumor cells. Immunolabeling with anti-CD133 antibody, $\times 200$. CD133: Cluster of differentiation 133.

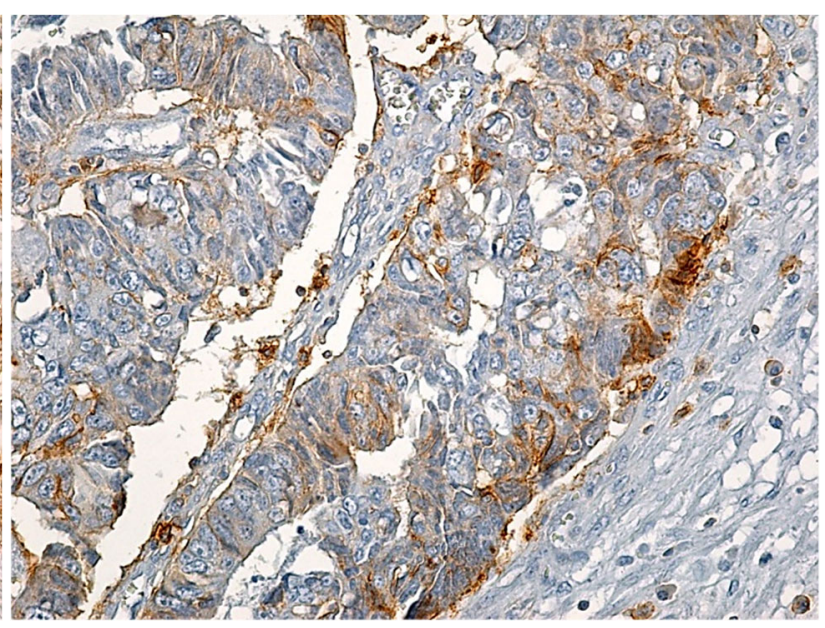

Figure 10 - Poorly differentiated colon adenocarcinoma with a weak reaction to CD44 within tumor cells. Immunolabeling with anti-CD44 antibody, $\times 200$. CD44: Cluster of differentiation 44.

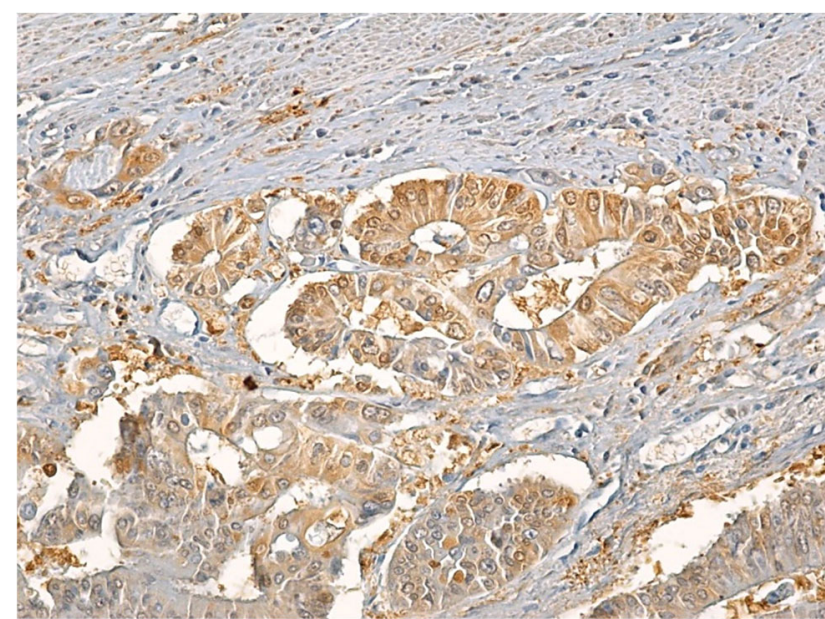

Figure 11 - Moderately differentiated adenocarcinoma with intense tumor cell reaction to ALDH1A1. Immunolabeling with anti-ALDH1A1 antibody, $\times 200$. ALDH1A1: Aldehyde dehydrogenase 1 family member A1.

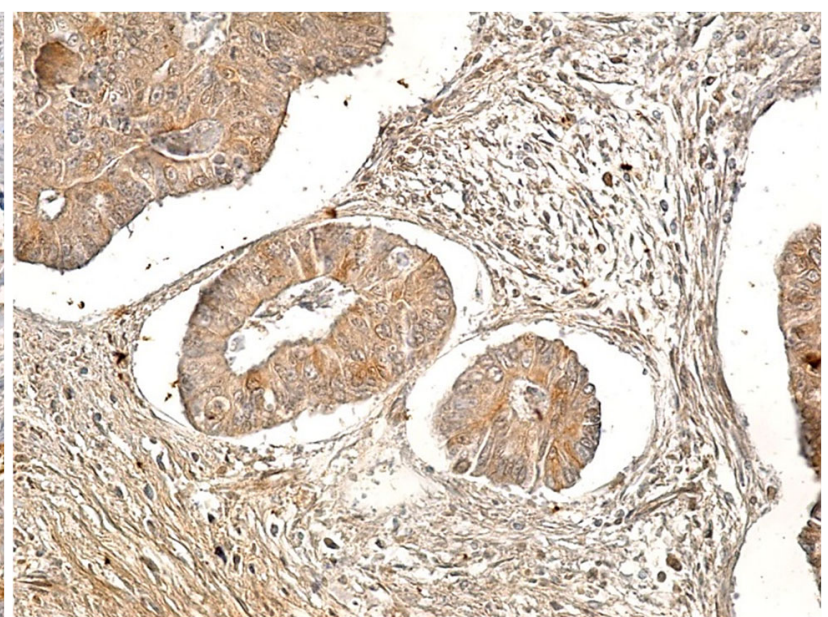

Figure 12 - Well-differentiated colon adenocarcinoma with intensely CD24-positive cells. Immunolabeling with anti-CD24 antibody, $\times 200$. CD24: Cluster of differentiation 24. 


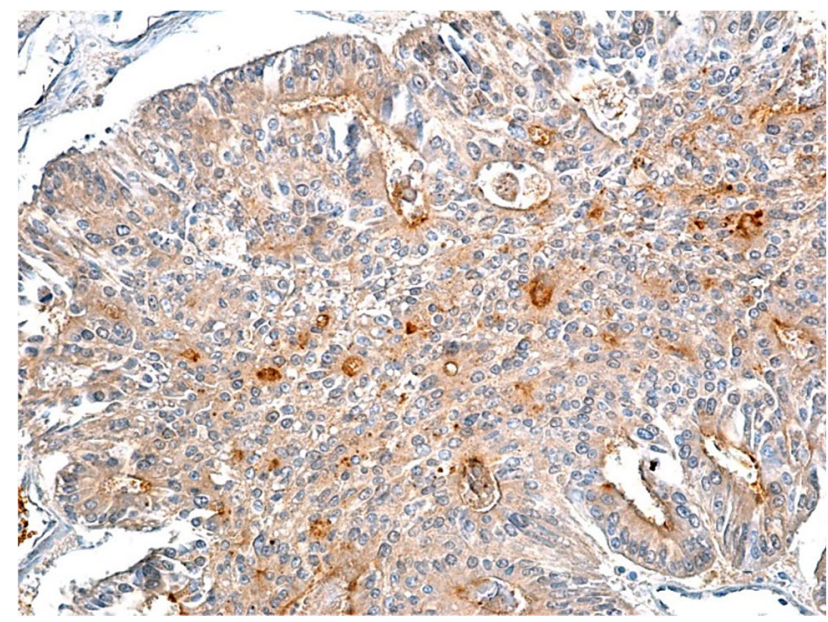

Figure 13 - Poorly differentiated colon adenocarcinoma with moderate immunohistochemical reaction to CD26 immunomarker. Immunolabeling with anti-CD26 antibody, $\times 200$. CD26: Cluster of differentiation 26.

\section{모 Discussions}

Despite the ever-increasing knowledge about tumor biology and recent advances when it comes to cancer treatments, this disease continues to present with a very high morbidity and mortality worldwide. According to data from $\mathrm{WHO}$ experts, cancer represents an important cause for mortality; in 2010, there were approximately 10 million deaths worldwide linked to cancer [17]. The high mortality rate continues to be mainly caused by delay in diagnosis, due to the asymptomatic or quasi-asymptomatic evolution of some cancer forms, due to high degree of recurrences and development of metastasis which destroy the structure and the function of the affected organs [18]. Therefore, cancer continues to represent a huge medical and socioeconomic burden in both developing and developed countries [3, 18, 19].

CRCs develop from the epithelial cells that lined the colon and rectal mucosa. The covering epithelium is very vulnerable to risk factors and allows the initiation of genetic mutations due to factors relating to local environment and the high replication rate of the intestinal epithelium cells.

Our histopathological study showed that there is a great degree of microscopic variability of CRCs, which is a result of various aspects of tumor cells but also variation within the tumor stroma and tumor microenvironment. Within the tumor structure, the cells were mainly formed of tubular glands, which were lined with a tall, columnar, and pseudostratified epithelium, with occasional PASpositive mucus producing caliciform cells. The glands presented with a wide and uneven lumen, with ramifications and at times with cell fragments within the lumen. Within the same tumor, we identified areas of well-differentiated adenocarcinoma but all we found mucinous areas and even signet-ring cells. The cellular pleomorphism was vastly expressed, which confirms the phenotypic variability of tumor cells forming colon and rectal tumors.

This marked variability was caused by the acquisition of genomic changes, which offer mutant cells and advantage when it comes to survival and growth when compared to normal cells [20]. The formation of some tumor cell phenotypes happens in the phase of malignant conversion, neoplasia initiation but also in the phases of tumor progression and metastasis, due to changes within the

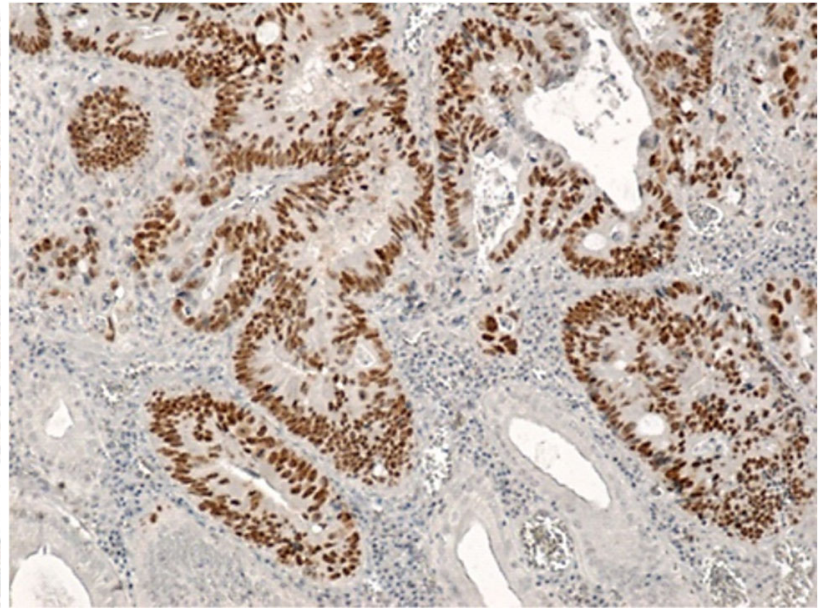

Figure 14 - Well-differentiated colon adenocarcinoma with intense reaction of tumor cells to p53 immunomarker. Immunolabeling with anti-p53 antibody, $\times 100$.

local microenvironment, which in turn generate a "selective pressure" on the "birth" of cell phenotypes adapted to local, environmental conditions $[21,22]$.

Within the colon and rectum, cell transformation can lead to the development of both malignant and benign tumors; the benign tumor still retains the possibility of later evolving towards a malignant form $[18,23]$.

In CRCs, within the structure of the tumor, besides neoplastic cells, we can find other type of cells (fibroblasts, immune cells, vascular cells) and extracellular connective matrix (ECM), which form the tumor microenvironment and constitute essential elements in tumor progression [24]. Tumor microenvironment is a complex morphological and molecular structure, which reflects the interaction between the tumor cells and the adjacent stromal cells, especially the interaction with fibroblasts and also inflammatory cells [25]. Is within this microenvironment that it is believed that mesenchymal stem cells (MSCs) develop, which later appear to have an essential role in tumor formation and maintaining the tumor microenvironment [26]. After migration within the microenvironment, MSCs differentiate in fibroblast-like cells (cancer-associated fibroblasts), a predominant stromal cell type, which are believed to be involved in colon cancer growth and "survival" [27, 28].

Under normal condition, the tissue fibroblasts are responsible for maintaining the integrity of the ECM through cell-cell direct contact or paracrine signaling through soluble factors that the synthetized and excreted within the ECM; also, normal fibroblasts can excursive various suppressive roles against cancer initiation and against metastatic cells [29].

Cancer-associated fibroblasts, which can form from either MSCs or modified local fibroblasts, become the dominant component of the tumor stroma and generate a series of pro-tumorigenic signals together with signals that inhibit the anti-tumor immune response which gives an opportunity to the cancer cells to proliferate intensely. To sustain further tumor progression and metastasis, cancerassociated fibroblasts secret enzymes involved in reshaping the ECM, growth factors, signaling molecules which continue to alter the tumor microenvironment [30].

The morphological component of tumor microenvironment is represented by the tumor stroma. In our 
study, the stroma was most often of a desmoplastic type, with the formation of dense collagen fibers, as a support structure for the tumor glands. Often, we also noted that the stroma had an aspect resembling soft connective tissue and more or less infiltrated with inflammatory cells.

Numerous studies have shown that tumor cells have the capacity to reshape the stroma and to establish a microenvironment that is favorable to their progression through the secretion of inflammatory cells recruiting factors and/or are involved in activating the stromal cells. In return, microenvironmental cells produce soluble factors (cytokines, chemokines, growth factors, proteases) which govern the growth, differentiation and tumor cell survival and therefore help tumor growth and progression. Compared to the cytokines these cells produce a high level of reactive oxygen species and nitrogen species, which can promote cancer and can induce genetic changes within the surrounding epithelium [31].

Studies completed in the last 30 years have shown that cancer tissues contain a small population of cells that have particular abilities, like self-renewal, long-life span, reduce proliferation rate, resistance to cytotoxic substances, properties which are similar to those of SCs contained in normal tissues and organs $[32,33]$. These cells called CSCs, have the capacity to generate progenitor cells characterized by increased proliferation rates, which ultimately determine the development and expansion of cancer tissue [34, 35]. CSCs were initially considered a cell population that has well defined molecular and phenotypic characteristic, but studies conducted in the last 10 years have shown that CSCs are a dynamic cell population, subjected to constant shaping by genetic, epigenetic, and microenvironmental factors [33].

Immunohistochemistry, cellular and molecular biology, and genetic studies have focused on the identification of the mechanisms through which CSCs determine tumor progression with a view to allow doctors to interfere with these processes and ultimately to improve CRC treatment.

CD133 was considered one of the IHC marker typically associated with colon CSCs in humans. In our study, we demonstrated that this particular immunomarker is not CSC specific but marks almost all differentiated tumor cells and even some stromal cells. New studies suggest that CD133 is expressed in both CSCs associated with colon tumors but also in non-CSCs as certain epitopes are present in both CSCs and non-CSCs [36]. Therefore, more than one study has shown that there are significant discrepancies between research results available to date due to differences between these IHC markers [35].

As per CD44 immunomarker, recent studies have shown that this is the most common CSC surface marker and plays an essential role in the communication between CSCs and the tumor microenvironment [37]. The molecular structure of CD44 acts as a receptor for hyaluronic acid and other components of the ECM allowing CSCs to identify changes in the environment and adapt their properties based on these changes and the new environment. We can therefore explain the existence of numerous SC phenotypes within a colon tumor.

Other studies have shown that CD44 is involved with CSCs survival, self-renewal and chemoresistance, which explains, at least in part, why CD44 is an essential structure to the adaptation of cancer cells to the new environment and why CD44 is needed for the growth, dissemination, and tumor cell metastasis [38-40].
In our study, CD44 immunomarker was more intensely expressed in poorly differentiated adenocarcinomas and a weaker expression in well and moderately differentiated adenocarcinomas.

In our study, the ALDH1A1 immunomarker had an intense reaction within the colon adenocarcinoma tumor cells, regardless of de degree of tumor differentiation. This microscopic aspect proves that ALDH1A1 is not only present in CSCs but also in other differentiated tumor cells. The data regarding the implication of ALDH1A1 immunomarker in colon cancer are yet contradictory [41, 42].

\section{a Conclusions}

Colon adenocarcinoma has an accentuated cellular pleomorphism, due to the formation of different clones of tumor cells, in the same tumor there are aspects of tubular adenocarcinoma, mucinous areas and even signet-ring cells. The tumor stroma was mainly of the desmoplastic type, but also of the lax type, more or less infiltrated with inflammatory cells. Evaluation of immunomarkers for CSCs showed that none of the markers used alone (CD133, CD44, ALDH1A1, CD24, CD26) show CSCs.

\section{Conflict of interests}

The authors declare that they have no conflict of interests.

\section{References}

[1] Kuipers EJ, Grady WM, Lieberman D, Seufferlein T, Sung JJ, Boelens PG, van de Velde CJH, Watanabe T. Colorectal cancer. Nat Rev Dis Primers, 2015, 1:15065. https://doi.org/ 10.1038/nrdp.2015.65 PMID: 27189416 PMCID: PMC4874655

[2] Siegel RL, Miller KD, Jemal A. Cancer statistics, 2018. CA Cancer J Clin, 2018, 68(1):7-30. https://doi.org/10.3322/caac. 21442 PMID: 29313949

[3] Ahechu P, Zozaya G, Martí P, Hernández-Lizoáin JL, Baixauli J, Unamuno X, Frühbeck G, Catalán V. NLRP3 inflammasome: a possible link between obesity-associated lowgrade chronic inflammation and colorectal cancer development. Front Immunol, 2018, 9:2918. https://doi.org/10.3389/fimmu. 2018.02918 PMID: 30619282 PMCID: PMC6297839

[4] Kolligs FT. Diagnostics and epidemiology of colorectal cancer. Visc Med, 2016, 32(3):158-164. https://doi.org/10.1159/000 446488 PMID: 27493942 PMCID: PMC4945785

[5] Bray F, Ferlay J, Soerjomataram I, Siegel RL, Torre LA, Jemal A. Global cancer statistics 2018: GLOBOCAN estimates of incidence and mortality worldwide for 36 cancers in 185 countries. CA Cancer J Clin, 2018, 68(6):394-424. https://doi.org/10.3322/ caac.21492. Erratum in: CA Cancer J Clin, 2020, 70(4):313. PMID: 30207593

[6] Martinez-Useros J, Garcia-Foncillas J. Obesity and colorectal cancer: molecular features of adipose tissue. J Transl Med, 2016, 14:21. https://doi.org/10.1186/s12967-016-0772-5 PMID: 26801617 PMCID: PMC4722674

[7] O'Keefe SJD. Diet, microorganisms and their metabolites, and colon cancer. Nat Rev Gastroenterol Hepatol, 2016, 13(12): 691-706. https://doi.org/10.1038/nrgastro.2016.165 PMID: 27848961 PMCID: PMC6312102

[8] Park J, Morley TS, Kim M, Clegg DJ, Scherer PE. Obesity and cancer - mechanisms underlying tumour progression and recurrence. Nat Rev Endocrinol, 2014, 10(8):455-465. https:// doi.org/10.1038/nrendo.2014.94 PMID: 24935119 PMCID: PMC4374431

[9] Schwartz B, Yehuda-Shnaidman E. Putative role of adipose tissue in growth and metabolism of colon cancer cells. Front Oncol, 2014, 4:164. https://doi.org/10.3389/fonc.2014.00164 PMID: 25019059 PMCID: PMC4071563

[10] Grady WM, Carethers JM. Genomic and epigenetic instability in colorectal cancer pathogenesis. Gastroenterology, 2008, 135(4):1079-1099. https://doi.org/10.1053/j.gastro.2008.07. 076 PMID: 18773902 PMCID: PMC2866182

[11] Mármol I, Sánchez-de-Diego C, Pradilla Dieste A, Cerrada E, Rodriguez Yoldi MJ. Colorectal carcinoma: a general overview 
and future perspectives in colorectal cancer. Int $\mathrm{J}$ Mol Sci, 2017, 18(1):197. https://doi.org/10.3390/ijms18010197 PMID: 28106826 PMCID: PMC5297828

[12] McDonald SAC, Preston SL, Lovell MJ, Wright NA, Jankowski JAZ Mechanisms of disease: from stem cells to colorectal cancer. Nat Clin Pract Gastroenterol Hepatol, 2006, 3(5):267-274 https://doi.org/10.1038/ncpgasthep0473 PMID: 16673006

[13] Schwitalla S, Fingerle AA, Cammareri P, Nebelsiek T, Göktuna SI Ziegler PK, Canli O, Heijmans J, Huels DJ, Moreaux G, Rupec RA Gerhard M, Schmid R, Barker N, Clevers H, Lang R, Neumann J, Kirchner T, Taketo MM, van den Brink GR, Sansom OJ, Arkan MC Greten FR. Intestinal tumorigenesis initiated by dedifferentiation and acquisition of stem-cell-like properties. Cell, 2013, 152(1-2): 25-38. https://doi.org/10.1016/j.cell.2012.12.012 PMID: 23273993

[14] Wicha MS, Liu S, Dontu G. Cancer stem cells: an old idea - a paradigm shift. Cancer Res, 2006, 66(4):1883-1890; discussion 1895-1896. https://doi.org/10.1158/0008-5472.CAN-05-3153 PMID: 16488983

[15] Dawood S, Austin L, Cristofanilli M. Cancer stem cells: implications for cancer therapy. Oncology (Williston Park), 2014, 28(12): 1101-1107, 1110. PMID: 25510809

[16] Hanahan D, Weinberg RA. Hallmarks of cancer: the next generation. Cell, 2011, 144(5):646-674. https://doi.org/10.1016/ j.cell.2011.02.013 PMID: 21376230

[17] Roslan NH, Makpol S, Mohd Yusof YA. A review on dietary intervention in obesity associated colon cancer. Asian Pac Cancer Prev, 2019, 20(5):1309-1319. https://doi.org/10.31557/ APJCP.2019.20.5.1309 PMID: 31127882 PMCID: PMC6857900

[18] Lei C, Zhao B, Liu L, Zeng X, Yu Z, Wang X. Expression and clinical significance of p62 protein in colon cancer. Medicine (Baltimore), 2020, 99(3):e18791. https://doi.org/10.1097/MD 0000000000018791 PMID: 32011477 PMCID: PMC7220407

[19] Pandurangan AK, Divya T, Kumar K, Dineshbabu V, Velavan B, Sudhandiran G. Colorectal carcinogenesis: insights into the cell death and signal transduction pathways: a review. World J Gastrointest Oncol, 2018, 10(9):244-259. https://doi.org/10. 4251/wjgo.v10.i9.244 PMID: 30254720 PMCID: PMC6147765

[20] Al Bakir I, Curtius K, Graham TA. From colitis to cancer: an evolutionary trajectory that merges maths and biology. Front Immunol, 2018, 9:2368. https://doi.org/10.3389/fimmu.2018. 02368 PMID: 30386335 PMCID: PMC6198656

[21] Gatenby RA, Gillies RJ. A microenvironmental model of carcinogenesis. Nat Rev Cancer, 2008, 8(1):56-61. https:// doi.org/10.1038/nrc2255 PMID: 18059462

[22] DeGregori J. Evolved tumor suppression: why are we so good at not getting cancer? Cancer Res, 2011, 71(11):37393744. https://doi.org/10.1158/0008-5472.CAN-11-0342 PMID: 21610109 PMCID: PMC3677553

[23] Subramaniam R, Mizoguchi A, Mizoguchi E. Mechanistic roles of epithelial and immune cell signaling during the development of colitis-associated cancer. Cancer Res Front, 2016, 2(1):121. https://doi.org/10.17980/2016.1 PMID: 27110580 PMCID: PMC4841680

[24] Peddareddigari VG, Wang D, Dubois RN. The tumor microenvironment in colorectal carcinogenesis. Cancer Microenviron, 2010, 3(1):149-166. https://doi.org/10.1007/s12307-010-003 8-3 PMID: 21209781 PMCID: PMC2990487

[25] Kidd S, Spaeth E, Watson K, Burks J, Lu H, Klopp A, Andreeff M Marini FC. Origins of the tumor microenvironment: quantitative assessment of adipose-derived and bone marrow-derived stroma. PLoS One, 2012, 7(2):e30563. https://doi.org/10.1371/ journal pone.0030563 PMID: 22363446 PMCID: PMC3282707

[26] Sell S. Stem cell origin of cancer and differentiation therapy. Crit Rev Oncol Hematol, 2004, 51(1):1-28. https://doi.org/10. 1016/j.critrevonc.2004.04.007 PMID: 15207251

[27] Kidd S, Spaeth E, Dembinski JL, Dietrich M, Watson K, Klopp A Battula VL, Weil M, Andreeff M, Marini FC. Direct evidence of mesenchymal stem cell tropism for tumor and wounding microenvironments using in vivo bioluminescent imaging. Stem Cells, 2009, 27(10):2614-2623. https://doi.org/10.1002/ stem.187 PMID: 19650040 PMCID: PMC4160730

[28] De Becker A, Van Riet I. Homing and migration of mesenchymal stromal cells: how to improve the efficacy of cell therapy?
World J Stem Cells, 2016, 8(3):73-87. https://doi.org/10.4252/ wjsc.v8.i3.73 PMID: 27022438 PMCID: PMC4807311

[29] Paland N, Kamer I, Kogan-Sakin I, Madar S, Goldfinger N, Rotter V. Differential influence of normal and cancer-associated fibroblasts on the growth of human epithelial cells in an in vitro cocultivation model of prostate cancer. Mol Cancer Res, 2009, 7(8):1212-1223. https://doi.org/10.1158/1541-7786.MCR-090073 PMID: 19671672

[30] Alkasalias T, Moyano-Galceran L, Arsenian-Henriksson M, Lehti K. Fibroblasts in the tumor microenvironment: shield or spear? Int J Mol Sci, 2018, 19(5):1532. https://doi.org/10. 3390/ijms19051532 PMID: 29883428 PMCID: PMC5983719

[31] Klampfer L. Cytokines, inflammation and colon cancer. Curr Cancer Drug Targets, 2011, 11(4):451-464. https://doi.org/10. 2174/156800911795538066 PMID: 21247378 PMCID: PMC 3540985

[32] Ricci-Vitiani L, Lombardi DG, Pilozzi E, Biffoni M, Todaro M, Peschle C, De Maria R. Identification and expansion of human colon-cancer-initiating cells. Nature, 2007, 445(7123):111-115. https://doi.org/10.1038/nature05384 PMID: 17122771

[33] Kreso A, Dick JE. Evolution of the cancer stem cell model. Cell Stem Cell, 2014, 14(3):275-291. https://doi.org/10.1016/j.stem. 2014.02.006 PMID: 24607403

[34] Todaro M, Gaggianesi M, Catalano V, Benfante A, lovino F, Biffoni M, Apuzzo T, Sperduti I, Volpe S, Cocorullo G, Gulotta G, Dieli F, De Maria R, Stassi G. CD44v6 is a marker of constitutive and reprogrammed cancer stem cells driving colon cancer metastasis. Cell Stem Cell, 2014, 14(3):342-356. https://doi.org/ 10.1016/j.stem.2014.01.009 PMID: 24607406

[35] Hatano Y, Fukuda S, Hisamatsu K, Hirata A, Hara A, Tomita H. Multifaceted interpretation of colon cancer stem cells. Int J Mol Sci, 2017, 18(7):1446. https://doi.org/10.3390/ijms18071446 PMID: 28678194 PMCID: PMC5535937

[36] Shmelkov SV, Butler JM, Hooper AT, Hormigo A, Kushner J, Milde T, St Clair R, Baljevic M, White I, Jin DK, Chadburn A, Murphy AJ, Valenzuela DM, Gale NW, Thurston G, Yancopoulos GD, D'Angelica M, Kemeny N, Lyden D, Rafii S. CD133 expression is not restricted to stem cells, and both CD133+ and CD133- metastatic colon cancer cells initiate tumors. J Clin Invest, 2008, 118(6):2111-2120. https://doi.org/ 10.1172/JCI34401 PMID: 18497886 PMCID: PMC2391278

[37] Naor D, Wallach-Dayan SB, Zahalka MA, Sionov RV. Involvement of CD44, a molecule with a thousand faces, in cancer dissemination. Semin Cancer Biol, 2008, 18(4):260-267. https:// doi.org/10.1016/j.semcancer.2008.03.015 PMID: 18467123

[38] Malanchi I, Santamaria-Martínez A, Susanto E, Peng H, Lehr HA Delaloye JF, Huelsken J. Interactions between cancer stem cells and their niche govern metastatic colonization. Nature, 2011, 481(7379):85-89. https://doi.org/10.1038/nature10694 PMID: 22158103

[39] Ju SY, Chiou SH, Su Y. Maintenance of the stemness in CD44(+) HCT-15 and HCT-116 human colon cancer cells requires miR-203 suppression. Stem Cell Res, 2014, 12(1): 86-100. https://doi.org/10.1016/j.scr.2013.09.011 PMID: 24145190

[40] Bourguignon LYW, Shiina M, Li JJ. Hyaluronan-CD44 interaction promotes oncogenic signaling, microRNA functions, chemoresistance, and radiation resistance in cancer stem cells leading to tumor progression. Adv Cancer Res, 2014, 123:255-275. https://doi.org/10.1016/B978-0-12-800092-2.00010-1 PMID: 25081533 PMCID: PMC6759082

[41] Kozovska Z, Patsalias A, Bajzik V, Durinikova E, Demkova L, Jargasova S, Smolkova B, Plava J, Kucerova L, Matuskova M. ALDH1A inhibition sensitizes colon cancer cells to chemotherapy. BMC Cancer, 2018, 18(1):656. https://doi.org/10.1186/ s12885-018-4572-6 PMID: 29902974 PMCID: PMC6003038

[42] Kahlert C, Gaitzsch E, Steinert G, Mogler C, Herpel E, Hoffmeister $M$, Jansen L, Benner A, Brenner $H$, ChangClaude J, Rahbari N, Schmidt T, Klupp F, Grabe N, Lahrmann B, Koch M, Halama N, Büchler M, Weitz J. Expression analysis of aldehyde dehydrogenase 1A1 (ALDH1A1) in colon and rectal cancer in association with prognosis and response to chemotherapy. Ann Surg Oncol, 2012, 19(13):4193-4201. https://doi.org/10.1245/s10434-012-2518-9 PMID: 22878609

\section{Corresponding author}

Daniel Sorin Ilie, MD, PhD Student, Doctoral School, Department of Histology, University of Medicine and Pharmacy of Craiova, 2 Petru Rareş Street, 200349 Craiova, Romania; Phone +40766-444 454, e-mail: dr.daniel.ilie@gmail.com 